\title{
Quantitative Analysis of Glycogen Repletion by Nuclear Magnetic Resonance Spectroscopy in the Conscious Rat
}

\author{
Gerald I. Shulman, Luciano Rossetti, Douglas L. Rothman, James B. Blair, and Douglas Smith \\ Division of Diabetes/Endocrinology, Departments of Medicine and Molecular Biology and Biophysics, Yale University, New Haven, \\ Connecticut 06511; Department of Biochemistry, West Virginia University Medical Center, Morgantown, West Virginia 26506; \\ Diabetes Unit, Massachusetts General Hospital, Boston, Massachusetts 02114
}

\section{Abstract}

In order to directly determine the amount of label exchange that occurs in the tricarboxylic cycle from labeled alanine and lactate after the ingestion of a glucose load $\left[1-{ }^{13}\right.$ Clglucose was administered by continuous intraduodenal infusion to awake catheterized rats to achieve steady state jugular venous glycemia (160 $\mathrm{mg} / \mathrm{dl}$ ) for $180 \mathrm{~min}$. Liver was freeze-clamped at 90 and 180 min, and perchloric acid extracts of the liver were subjected to ${ }^{13} \mathrm{C}$ and ${ }^{1} \mathrm{H}$ nuclear magnetic resonance analysis. Dilution in the oxaloacetate pool was determined by comparing the intrahepatic ${ }^{13} \mathrm{C}$ enrichments of $\mathrm{C2}, \mathrm{C} 3$ positions of glutamate with the $\mathrm{C2}$, $\mathrm{C} 3$ positions of alanine and lactate. In addition steady state flux equations were derived for calculation of relative fluxes through pyruvate dehydrogenase/TCA cycle flux and pyruvate kinase flux/total pyruvate utilization.

After glucose ingestion in a 24-h fasted rat direct conversion of glucose was responsible for $34 \%$ of glycogen. The intrahepatic dilution factor for labeled pyruvate in the oxaloacetate pool was 2.4. Using this factor, alanine and lactate contributed $\sim 55 \%$ to glycogen formation. Pyruvate dehydrogenase flux ranged between 24 and $35 \%$ of total acetyl-coenzyme A (CoA) production and pyruvate kinase flux relative to total pyruvate utilization was $\sim 40 \%$.

\section{Introduction}

There is increasing evidence that the majority of hepatic glycogen repletion after an oral glucose load in rat and man occurs via a gluconeogenic process (1-8). It has been hypothesized that lactate and alanine are the primary gluconeogenic precursors for glycogen formation $(2,4-6)$. In a previous study using nuclear magnetic resonance spectroscopy (NMR), ${ }^{1}$ we estimated that a minimum of $10-28 \%$ of newly formed glycogen was derived from alanine/lactate (6). Quantitative contribution of these precursors to glycogenesis has been difficult to determine due to

Presented in part at the National Meeting of the American Diabetes Association, Anaheim, CA, 1986, and at the 22nd Annual Meeting of the European Society for the Study of Diabetes, Rome, Italy, 1986.

Address reprint requests to Dr. Shulman, Yale University.

Received for publication 1 December 1986 and in revised form 3 March 1987.

1. Abbreviations used in this paper: APE, atom percent excess; NMR, nuclear magnetic resonance; OAA, oxaloacetate; PV, portal vein; TCA, tricarboxylic cycle.

J. Clin. Invest.

(c) The American Society for Clinical Investigation, Inc.

0021-9738/87/08/0387/07 $\$ 2.00$

Volume 80, August 1987, 387-393 the exchange of carbon label in the oxaloacetate (OAA) pool, however, which serves as a common intermediate both in the gluconeogenic pathway and in the tricarboxylic (TCA) cycle (9-11).

To directly determine the amount of label exchange that occurs in the TCA cycle from labeled alanine and lactate after ingestion of a glucose load, $\left[1{ }^{13} \mathrm{C}\right]$ glucose was administered $(99 \%$ enriched) by constant intraduodenal infusion, and the ${ }^{13} \mathrm{C}$ enrichments examined in intrahepatic glutamate, alanine, and lactate under steady state conditions. If the enrichment in carbon positions 2 and 3 of OAA could be determined, it would be possible to directly quantitate the dilution of label in the OAA pool. Presently, this is not possible to do by ${ }^{13} \mathrm{C}-\mathrm{NMR}$ because of the very low intracellular concentration of this compound. However, the enrichment in carbon positions 2 and 3 of glutamate can readily be determined using ${ }^{13} \mathrm{C}-\mathrm{NMR}$. Since glutamate is believed to be in equilibration with alpha-ketoglutarate (12), the ratio of label in the C2, C3 positions of alanine/lactate to the $\mathrm{C} 2, \mathrm{C} 3$ of glutamate during steady state should yield an index to the amount of label exchange that occurs when labeled alanine and lactate pass through the oxaloacetate pool. It is important that this dilution factor can be determined sequentially throughout the postcibal period. This dynamic assessment is crucial because intracellular enzymatic activity (i.e., pyruvate dehydrogenase, pyruvate kinase, etc.) may change following glucose ingestion and thus alter the dilution factor (11).

Another advantage of the present study design is that it allows in vivo quantitation of the relative fluxes through pyruvate dehydrogenase/TCA cycle flux and pyruvate kinase/total pyruvate utilization. If the enrichments in the different carbon positions of glutamate, alanine, and lactate under steady state conditions are known, a series of inflow = outflow equations can be developed as described $(11,13-16)$ to quantitate the relative fluxes of pyruvate dehydrogenase/TCA cycle flux and pyruvate kinase/ total pyruvate utilization in vivo in a conscious, unstressed rat (see Appendix).

\section{Methods}

Animals. Male Sprague-Dawley rats weighing between 250 and $330 \mathrm{~g}$ purchased from Hilltop Lab Animals (Chatsworth, CA) were used. They were maintained on standard rat chow (Ralston-Purina Co., St. Louis, MO) and were housed in an environmentally controlled room with a 12-h light/dark cycle. $1 \mathrm{wk}$ before the study an internal jugular catheter, extending to the right atrium, and an intraduodenal catheter were implanted. The catheters were filled with heparin/polyvinylpyrrolidone solution, sealed, and tunneled subcutaneously around the side of the neck to the back of the head. The catheters were externalized through a skin incision through the back of the neck. Only those animals that were active and eating normally within $36 \mathrm{~h}$ after the surgery were used. All rats were fasted $24 \mathrm{~h}$ before the study to deplete liver glycogen. At 0900 hours on the day of the study a prime- $(0.7 \mathrm{~g} / \mathrm{kg})$ constant $(35 \mathrm{mg} /$ 
$\mathrm{kg} \cdot \mathrm{min})$ infusion of $\left[1-{ }^{13} \mathrm{C}\right] \mathrm{glucose}(99 \%$ enriched, $15 \mathrm{~g} / \mathrm{dl})$ was begun via the duodenal catheter and continued throughout the study. The [1$\left.{ }^{13} \mathrm{C}\right]$ glucose meal was also labeled with $\left[3-{ }^{3} \mathrm{H}\right]$ glucose $(0.10 \mu \mathrm{Ci} / \mathrm{min})(n$ $=5)$ or $\left[1-{ }^{14} \mathrm{C}\right]$ glucose $(0.20 \mu \mathrm{Ci} / \mathrm{min})(n=4)$ to monitor the initial time course and constancy of the plasma $\left[{ }^{3} \mathrm{H}\right]$ glucose and $\left[{ }^{14} \mathrm{C}\right]$ lactate specific activities. During the intraduodenal glucose infusion, the animals were allowed to roam freely in their cages. Blood samples for plasma glucose, $\left[{ }^{3} \mathrm{H}\right]$ glucose and $\left[{ }^{14} \mathrm{C}\right]$ lactate specific activities were taken at 5 -min intervals during the first $60 \mathrm{~min}$ of the study and at 15-30-min intervals thereafter, so that a time averaged enrichment for glucose and lactate could be calculated. The average blood sample was usually $<200 \mu l$ and the blood volume was maintained by transfusing the animal with blood taken from a litter mate as previously described (17). Six rats were killed at $90 \mathrm{~min}$ after the start of the glucose infusion and five rats were killed after $180 \mathrm{~min}$. At the time of death, animals were injected with $2 \%$ sodium thiamylal (Biotal, Bio-Centric, St. Joseph, MO) $(1 \mathrm{ml} / \mathrm{kg}$ body $w t)$. The abdomen was quickly opened and a portal vein blood sample was taken. The liver was then freeze-clamped with aluminum tongs precooled to $-77^{\circ} \mathrm{C}$ with liquid nitrogen and weighed. The time from the injection of the anesthetic until freeze clamping of the liver was $<60 \mathrm{~s}$. All tissue samples were frozen at $-30^{\circ} \mathrm{C}$ for subsequent analysis. A group of four control animals were treated in an identical fashion (i.e., diet, housing, catheter insertion, 24-h fast, sacrifice, etc.). In this group no glucose was administered and liver samples were obtained for determination of glycogen concentration as described above.

\section{Analytical procedures}

Glucose concentrations in plasma and tissue extracts were determined using a Beckman glucose analyzer (Beckman Instruments, Inc., Palo Alto, CA) and plasma insulin by radioimmunoassay using porcine insulin standards. $\left[{ }^{3} \mathrm{H}\right]$ Glucose and lactate in plasma were quantitated as previously described $(6,18)$. $\left[{ }^{14} \mathrm{C}\right]$ Lactate in plasma was quantitated by an ion exchange procedure where $50 \mu$ l of plasma was added to a pencil column containing $1 \mathrm{ml}$ bed volume of AG-2-X8 acetate (100-200 meshes, Bio-Rad Laboratories, Richmond, CA). The column was washed with $4 \mathrm{ml} \mathrm{H}_{2} \mathrm{O}$ and acidified with $0.8 \mathrm{ml}$ of $1 \mathrm{~N} \mathrm{HCl}$. The lactate was then eluted with $4 \mathrm{ml}$ of $1 \mathrm{~N} \mathrm{HCl}$ and collected in a scintillation vial to which $15 \mathrm{ml}$ of ScintiVerse II (Fisher Scientific Co., Fair Lawn, NJ) was added and the ${ }^{14} \mathrm{C}$ counts in the sample were quantitated in a $\beta$-liquid scintillation counter. This procedure routinely gave recoveries $>95 \%$ for $\left[{ }^{14} \mathrm{C}\right]$ lactate and removed $>95 \%$ of $\left[{ }^{14} \mathrm{C}\right]$ glucose and $\left[{ }^{14} \mathrm{C}\right]$ alanine. Liver extracts were made using $0.9 \mathrm{~N}$ perchloric acid (PCA) and 99\% ethanol to precipitate the glycogen. The glycogen from the PCA pellet was then extracted and digested to glucose as previously described (6).

Lactate, glutamate, alanine and, in five experiments, aspartate, were semipurified from the PCA liver extract by means of a $(0.9 \times 150 \mathrm{~cm})$ Dowex-50 (200-400 mesh) column equilibrated with $0.1 \mathrm{M}$ ammonium formate, pH 3.0 as previously described (19). The alanine and lactate fractions were then lyophilyzed, brought up in $99.3 \% \mathrm{D}_{2} \mathrm{O}$ and subjected to NMR analysis to determine their ${ }^{13} \mathrm{C}$ fractional enrichment in the $\mathrm{C} 3$ position. The fractions were then combined along with the glutamate and aspartate fractions and subjected to ${ }^{13} \mathrm{C}-\mathrm{NMR}$ analysis to determine the relative ${ }^{13} \mathrm{C}$ percent labeling in the different positions of alanine, lactate, glutamate, and aspartate. Amino acid analysis was then performed on the same sample by an automated ion exchange chromatographic technique (Dionex 0-500, Dionex Corporation, Sunnyvale, CA) with an L6 column and lithium citrate buffer to calculate the absolute enrichment of the different positions (Eq. 2).

NMR methodology. ${ }^{13} \mathrm{C}-\mathrm{NMR}$ spectra of glucose and the combined samples of semipurified alanine, lactate, glutamate, and aspartate obtained from the PCA extracts of liver described above were taken at 125.76 MHz in a spectrometer (WM 500, Bruker Instruments, Inc., Billerica, MA). The samples were placed in standard 5-mm NMR tubes and the spectra were obtained using a standard 5-mm ${ }^{13} \mathrm{C}$-NMR probe. A $45^{\circ}$ pulse was repeated every $3 \mathrm{~s}$ for $1-12$ h $(3,600-10,000$ scans). Spectra were acquired with 4,096 data points over a sweep width of $10,000 \mathrm{~Hz}$ centered at 45 parts per million (ppm) (relative to $\beta$-D-glucose C-1 at $96.8 \mathrm{ppm}$ ) (0.205 ms acquisition time). Broad band proton noise de- coupling (2-5 W) centered $1 \mathrm{ppm}$ upfield from water was on only during the acquisition time to avoid the development of the nuclear Overhauser effect. The spectral parameters used allowed the intensities $\mathrm{C1}-\mathrm{C} 6$ of glucose, C2, C3 alanine, C2, C3 lactate, C2, C3, C4 glutamate, and C2, C3 aspartate resonances to be compared without $T_{1}$ (relaxation time) and nuclear Overhauser effect corrections. Small corrections were made for off-resonance effects. The carboxyl groups of alanine, lactate, glutamate, and aspartate were not quantitated since under the conditions of our spectra acquisition these groups were not fully relaxed due to their long $T_{1}$ 's. Resonance intensities were determined by computer integration and by manually cutting out and weighing plotted resonances; both methods yielded similar results. All of our spectra had an average signal to noise ratio $>25$ to 1 , which gave a maximum variability of peak quantitation of $\pm 5 \%$.

The ${ }^{13} \mathrm{C}$-fractional enrichment of the $\mathrm{C}-1$ position of each glucose sample was determined from ${ }^{1} \mathrm{H}-\mathrm{NMR}$ spectra at $360.13 \mathrm{MHz}$ in a standard ${ }^{1} \mathrm{H}-\mathrm{NMR}$ probe. A $45^{\circ}$ pulse angle $(3 \mu \mathrm{s})$ with a 10 -s relaxation delay was used. During the relaxation delay, the water and deuterium (HDO) resonance was saturated with a single radio frequency field of 50 $\mathrm{mW}$ (20). Spectra were acquired with a sweep width of $5,000 \mathrm{~Hz}$ centered at the HDO resonance in 8192 data points $(0.819 \mathrm{~ms}$ acquisition time). Samples were heated to $340^{\circ} \mathrm{K}$ to shift the HDO resonance upfield from the $\mathrm{C}-1$ proton resonance of alpha-D-glucose.

The ${ }^{13} \mathrm{C}$-fractional enrichment of portal vein plasma $\mathrm{C}$-1 glucose, and $\mathrm{C}-3$ lactate were determined from ${ }^{1} \mathrm{H}-\mathrm{NMR}$ spectra using a homonuclear double resonance spin echo difference sequence $(21,22)$. A 10-s relaxation delay was used for the glucose and a 15-s delay for lactate and alanine determinations. During the relaxation delay, the HDO resonance was saturated with a $50-\mathrm{mW}$ single radio frequency field (20). During the spin echo $\gamma$ delay ( $136 \mathrm{~ms}$ for glucose, $68 \mathrm{~ms}$ for lactate and alanine), single frequency ${ }^{1} \mathrm{H}$-decoupling was applied at $50 \mathrm{~mW}$. All other spectral parameters were as described above. The spectral parameters used allowed the intensities of the proton resonances from protons bonded to ${ }^{13} \mathrm{C}$ - and ${ }^{12} \mathrm{C}$-nuclei to be compared without $\mathrm{T}_{1}$ or $\mathrm{T}_{2}$ corrections. The ${ }^{13} \mathrm{C}$-fractional enrichment of $\mathrm{C} 3$ Alanine (A3) and $\mathrm{C} 3$ lactate (L3) obtained from the PCA extracts of liver were determined by ${ }^{1} \mathrm{H}$ NMR at $500 \mathrm{MHz}$ in the Bruker WM 500 spectrometer. The samples were placed in a standard $5 \mathrm{~mm}$ NMR tube and the spectra were obtained using a standard $5 \mathrm{~mm}{ }^{\prime} \mathrm{H}-\mathrm{NMR}$ probe. A $45^{\circ}$ pulse was repeated every $3 \mathrm{~s}$ for $2-4 \mathrm{~h}(2,400-4,800$ scans). Spectra were acquired with 4096 data points over a sweep width of $5,618 \mathrm{~Hz}$ centered at $9,032 \mathrm{~Hz}$.

\section{Materials}

$\left[1-{ }^{13} \mathrm{C}\right]$ Glucose (99\% enriched) was purchased from Cambridge Isotope Laboratories (Cambridge, MA) and $\left[1-{ }^{14} \mathrm{C}\right]$ glucose and $\left[3-{ }^{3} \mathrm{H}\right]$ glucose from New England Nuclear (Boston, MA).

\section{Calculations}

The ${ }^{13} \mathrm{C}$ labeling and correction for the small amount of unenriched glycogen initially present for each of the six glucose carbon peaks was computed as previously described (6).

The percent glycogen synthesized by the direct pathway was determined by the following equation:

Percent glycogen synthesized via direct pathway

$=\frac{(\mathrm{GL} 1-\mathrm{GL} 6) \times 100}{\mathrm{GL} 1_{\mathrm{pv}} \times 0.80}$

where GL1 and GL6 represent the ${ }^{13} \mathrm{C}$ atom percent excess (APE) in positions one and six of glucose in glycogen at the end of the study, GL $1_{p v}$ represents the APE in position one of portal vein glucose. For these calculations enrichments of glucose and alanine/lactate were adjusted for the time it took to reach steady state. For glucose it required $\sim 60 \mathrm{~min}$ and for alanine/lactate it required $\sim 100 \mathrm{~min}$ after the start of the glucose infusion before a steady state plasma enrichment/specific activity of each of these compounds was achieved. During these initial time intervals an average enrichment/specific activity was calculated by integrating the area under the initial time course from 0 to $135 \mathrm{~min}$ for 
$\left[{ }^{3} \mathrm{H}\right]$ glucose and $\left[{ }^{14} \mathrm{C}\right]$ lactate specific activities (Fig. 1) and time averaged with the steady state enrichment/specific activity during the remainder of the study. From these calculations the following adjustments were made: for $\left[1-{ }^{13} \mathrm{C}\right]$ glucose the adjustment was $0.80 \pm 0.05(n=5) \times \mathrm{pv}[1-$ $\left.{ }^{13} \mathrm{C}\right]$ glucose enrichment (APE); for $\left[3-{ }^{13} \mathrm{C}\right]$ alanine/lactate the adjustment was $0.69 \pm 0.04(n=4) \times\left[\right.$ intrahepatic $\left[2-{ }^{13} \mathrm{C}\right] \mathrm{ala} / \mathrm{lac}(\mathrm{APE})+\left[3-{ }^{13} \mathrm{C}\right] \mathrm{ala} /$ lac (APE)].

[where APE $=$ total ${ }^{13} \mathrm{C}$ enrichment $-1.1 \%$ (natural ${ }^{13} \mathrm{C}$ abundance) $]$

To calculate the absolute ${ }^{13} \mathrm{C}$ enrichments in the different positions of glutamate from the relative ${ }^{13} \mathrm{C}$ enrichments in alanine, lactate, glutamate, and aspartate, the following formula was used:

${ }^{13} \mathrm{C}_{3}$ alanine enrichment $\times \frac{\text { [alanine] }}{\text { [glutamate] }} \times \frac{{ }^{13} \mathrm{C} \text { glutamate } \mathrm{PI}}{{ }^{13} \mathrm{C}_{3} \text { alanine } \mathrm{PI}}$

where ${ }^{13} \mathrm{C}_{3}$ alanine is the enrichment in the $\mathrm{C} 3$ position of alanine as determined by ${ }^{1} \mathrm{H}-\mathrm{NMR}$ and [alanine] and [glutamate] are the concentrations of the respective amino acids in the sample as determined by amino acid analysis. $\left[{ }^{13} \mathrm{C}\right]$ Glutamate $\mathrm{PI}$ is the ${ }^{13} \mathrm{C}$-NMR peak integral for the particular carbon position (i.e., $\mathrm{C} 2, \mathrm{C} 3$, or $\mathrm{C} 4$ ) in glutamate, ${ }^{13} \mathrm{C}_{3}$ alanine $\mathrm{PI}$ is the ${ }^{13} \mathrm{C}$-NMR peak integral for the $\mathrm{C} 3$ position in alanine. The absolute enrichments for the individual enrichments of aspartate were calculated in the same way.

The dilution factor (DF) for alanine and lactate as they traverse the oxaloacetate pool was calculated as follows:

$(D F)=\frac{A 2 / L 2+A 3 / L 3}{G 2+G 3}$,

where $\mathrm{A} 2 / \mathrm{L} 2, \mathrm{~A} 3 / \mathrm{L} 3$, and $\mathrm{G} 2, \mathrm{G} 3$ represent the ${ }^{13} \mathrm{C}$ APE for those respective positions in alanine/lactate (averaged) and glutamate.

To calculate the amount of glycogen synthesized via the indirect pathway from alanine/lactate, the following formula was used:

Percent glycogen synthesized from ala/lac

$=\frac{(\mathrm{GL} 5+\mathrm{GL} 6) \times \mathrm{DF} \times 100}{\mathrm{~A} 2 / \mathrm{L} 2+\mathrm{A} 3 / \mathrm{L} 3 \times 0.69^{*}}$

where GL5 and GL6 are the ${ }^{13} \mathrm{C}$ APE in the fifth and sixth position of the glucose molecule and A2/L2 and A3/L3 are the average ${ }^{13} \mathrm{C}$ APE for intrahepatic alanine/lactate in the $\mathrm{C} 2$ and $\mathrm{C} 3$ positions and $\mathrm{DF}$ is the dilution factor as described in Eq. 3 all averaged between 90 and 180 min. The individual enrichments for G5 and G6 are used instead of 2 $\times$ G5 to take into account the asymmetry of label in OAA due to the incomplete equilibration between malate and fumarate (14).

Equations for the relative carbon flux through pyruvate dehydrogenase compared to the TCA cycle and through pyruvate kinase compared to total pyruvate utilization are shown below. The derivation of these equations was based upon the assumption of steady state conditions for glutamate and can be found in Appendix:

$\frac{\text { Pyruvate dehydrogenase flux }}{\text { TCA cycle flux }}=\frac{\text { G4 }}{\mathrm{A} 3 / \mathrm{L} 3}$

$\frac{\text { Pyruvate kinase flux }}{\text { total pyruvate utilization }}=\frac{A 2 / L 2}{(G 2+G 3) / 2}$

where G2, G3, G4, and A2/L2, A3/L3 are the average APE for the respective positions in glutamate or alanine/lactate.

Data in the text, tables, and figures are given as mean values \pm SEM. Statistical comparisons were made using the two tailed Student $t$ test.

\section{Results}

Fig. 1 shows the time course for the jugular venous glucose and lactate concentrations $(a)$ and $\left[3-{ }^{3} \mathrm{H}\right]$ glucose and $\left[{ }^{14} \mathrm{C}\right]$ lactate specific activities $(b)$ after the intraduodenal infusion of glucose labeled with $1-{ }^{13} \mathrm{C}$ and either $\left[3-{ }^{3} \mathrm{H}\right]$ glucose or $\left[1-{ }^{14} \mathrm{C}\right]$ glucose.
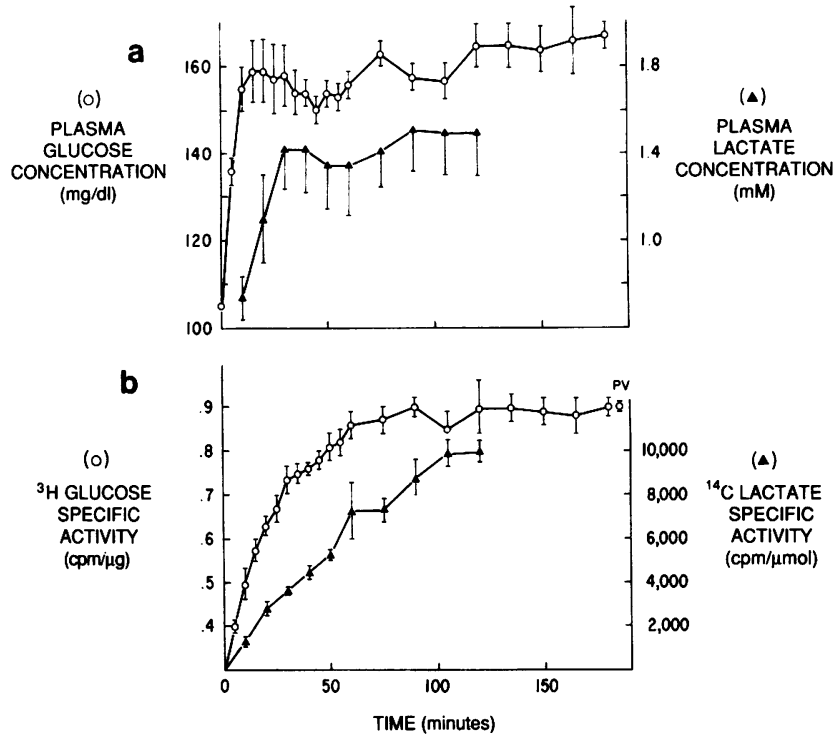

Figure 1. Time course for plasma glucose and plasma lactate concentration $(a)$ and $\left[3-{ }^{3} \mathrm{H}\right]$ glucose and $\left[{ }^{14} \mathrm{C}\right]$ lactate specific activities $(b)$. The intraduodenal infusion of $\left[1{ }^{13} \mathrm{C}\right] \mathrm{glucose}(15 \mathrm{~g} / \mathrm{dl}, 99 \%$ enriched) with either $\left[{ }^{3} \mathrm{H}-3\right]$ glucose or $\left[1-{ }^{14} \mathrm{C}\right]$ glucose was begun at $t=0 \mathrm{~min}$. $\mathrm{PV}$, portal vein $\left[{ }^{3} \mathrm{H}\right]$ glucose specific activity at $t=180 \mathrm{~min}$.

During the basal period, the plasma glucose concentration was $105 \pm 3 \mathrm{mg} / \mathrm{dl}$ and rose to a plateau of $\sim 160 \mathrm{mg} / \mathrm{dl}$ by $30 \mathrm{~min}$. The mean portal vein glucose was $202 \pm 8 \mathrm{mg} / \mathrm{dl}$ at $90 \mathrm{~min}$ and $194 \pm 6 \mathrm{mg} / \mathrm{dl}$ at $180 \mathrm{~min}$. The mean plasma lactate concentration at $10 \mathrm{~min}$ was $0.74 \pm 0.12 \mathrm{mM}$ and rose to a plateau value of $1.51 \pm 0.20 \mathrm{mM}$ by $90 \mathrm{~min}$. The tritiated glucose specific activity reached a plateau by 60 min and remained constant until the end of the experiment. The $\left[{ }^{14} \mathrm{C}\right]$ lactate specific activity reached a plateau at $\sim 100 \mathrm{~min}$ and also remained constant for the duration of the study. The mean plasma insulin during the basal period was $11 \pm 2 \mu \mathrm{U} / \mathrm{ml}(n=5)$ and rose to $42 \pm 12 \mu \mathrm{U} / \mathrm{ml}$ at $15 \mathrm{~min}$ and remained constant for the remainder of the 180 min glucose infusion. The mean portal vein insulin concentration was $67 \pm 25 \mu \mathrm{U} / \mathrm{ml}$ at the end of the study. Fasting liver glycogen concentration was $0.43 \pm 0.1 \mathrm{~g} / 100 \mathrm{mg}(n=4)$ and increased to $3.31 \pm 0.5 \mathrm{~g} / 100 \mathrm{mg}$ at $180 \mathrm{~min}(n=5, P<0.05)$ to yield a mean glycogen synthetic rate of $\sim 0.89 \mu \mathrm{M} / \mathrm{g}$ liver-min.

The ${ }^{13} \mathrm{C}$ APE in the C1-C6 positions of the glucosyl unit of glycogen and the $\mathrm{Cl}$ position of portal vein glucose can be seen in Table I. As we (6) and others (23-27) have previously demonstrated starting with $\mathrm{Cl}$ labeled glucose, most of the label in glycogen appears in the $\mathrm{Cl}$ position of the glucosyl unit. In addition there is very little difference in the labeling pattern between the 90 - and 180 -min values for either the ${ }^{13} \mathrm{C}$ percent labeling in the different positions of the glucosyl units of glycogen or in the portal vein $\mathrm{Cl}$ glucose ${ }^{13} \mathrm{C}$ enrichment (Table I); these findings indicate that steady conditions had been reached by $\sim 90 \mathrm{~min}$, and is consistent with our previous observations (6). The percent contribution of glucose to glycogen formation by the direct pathway (i.e., glucose $\rightarrow$ glucose-6-P $\rightarrow$ glucose-1-P $\rightarrow$ UDPglucose $\rightarrow$ glycogen) can be determined by Eq. 1 using the mean ${ }^{13} \mathrm{C}$ percent labeling data in Table I and was found to be $34 \%$.

A representative ${ }^{13} \mathrm{C}-\mathrm{NMR}$ spectra of intrahepatic alanine, lactate, glutamate, and aspartate is shown in Fig. 2 (obtained under conditions described in Methods). As can be seen, the C2 and $\mathrm{C} 3$ positions for alanine, lactate, aspartate, and the $\mathrm{C} 2, \mathrm{C} 3$ 
Table I. Percent Labeling for C1-C6 Glucose (GL1-GL6) in Glycogen, Portal Vein Cl Glucose (GL1 po) and C3 Lactate $\left(L 3_{p o}\right)$ Obtained at $90 \mathrm{~min}$ and $180 \mathrm{~min}$

\begin{tabular}{clllllll}
\hline Glycogen glucose & & & & & & Portal vein & Portal vein \\
\hline $90^{\prime}(n=6)$ & & & & & & & \\
GL1 & GL2 & GL3 & GL4 & GL5 & GL6 & GL1 $_{\text {pv }}$ & L3 $_{\text {pv }}$ \\
$24.2 \pm 4.0$ & $1.0 \pm 0.3$ & $0.4 \pm 0.1$ & $0.5 \pm 0.1$ & $1.4 \pm 0.3$ & $2.6 \pm 0.4$ & $87.9 \pm 1.4$ & $28.0 \pm 1.1$ \\
$180^{\prime}(n=5)$ & & & & & & & \\
$30.3 \pm 3.0$ & $1.1 \pm 0.2$ & $0.3 \pm 0.1$ & $0.2 \pm 0.1$ & $1.2 \pm 0.2$ & $1.8 \pm 0.4$ & $90.2 \pm 1.2$ & $31.9 \pm 1.7$ \\
$\begin{array}{c}\text { Overall mean } \\
26.6 \pm 2.7\end{array}$ & $1.0 \pm 0.2$ & $0.4 \pm 0.1$ & $0.3 \pm 0.1$ & $1.3 \pm 0.2$ & $2.3 \pm 0.3$ & $89.2 \pm 0.9$ & $30.1 \pm 0.9$ \\
\hline
\end{tabular}

All values expressed in APE \pm SEM.

and $\mathrm{C} 4$ positions of glutamate can easily be discerned. The peak integrals reflect the relative ${ }^{13} \mathrm{C}$ percent labeling in the respective positions. From these spectra the ${ }^{13} \mathrm{C}$ labeling in the different positions of alanine, lactate and glutamate can be determined (Eq. 2) and are shown in Table II. The average enrichments at the $\mathrm{C} 2$ and $\mathrm{C} 3$ positions at $90 \mathrm{~min}$ were $2.2 \pm 1.0$ (A2), $17.4 \pm 1.8$ (A3) APE, respectively, for alanine, and $2.9 \pm 0.5$ (L2) and $19.4 \pm 1.3$ (L3) APE, respectively, for lactate. At $180 \mathrm{~min}$ the enrichments in positions 2 and 3 had not changed appreciably: $2.2 \pm 0.5$ (A2) and $20.5 \pm 0.8$ (A3) APE, respectively, for alanine and 1.6 $\pm 0.4(\mathrm{~L} 2)$ and $24.0 \pm 1.7$ (L3) APE, respectively, for lactate.

The enrichments for the $\mathrm{C} 2$ and $\mathrm{C} 3$ positions of glutamate were $6.1 \pm 1.2(\mathrm{G} 2)$ and 3.3 $\pm 0.7(\mathrm{G} 3)$ APE, respectively, at 90 min and 6.1 $\pm 0.9(\mathrm{G} 2)$ and 5.0 $\pm 0.8(\mathrm{G} 3)$ APE, respectively, at $180 \mathrm{~min}$. Of note was the observed increase in C4 from 4.6 \pm 1.4 (G4) APE at $90 \mathrm{~min}$ to $7.9 \pm 1.3(\mathrm{G} 4) \mathrm{APE}(P<0.05)$ at 180 min reflecting an increase in pyruvate dehydrogenase flux (see Discussion) and a slight increase in $\mathrm{C} 3$ alanine and lactate enrichments. Of further note was the ratio of $\mathrm{C} 2$ glutamate/C3 glutamate. If malate equilibrates completely with fumarate this ratio would be 1 . As calculated from the mean data in Table II the C2 glutamate/C3 glutamate ratio is 1.8 at $90 \mathrm{~min}$ and 1.2 at 180 min, suggesting that equilibration between malate and fumarate is not complete. This disequilibration is also reflected and in fair agreement with the ratio of enrichment in C6 glucose/ C5 glucose being 1.9 at $90 \mathrm{~min}$ and 1.5 at $180 \mathrm{~min}$, although any futile cycling of label from glucose down to the level of the triose phosphates and back up into glycogen will further increase this ratio above that due to disequilibration between malate and fumarate. In five animals (90 $\mathrm{min} ; n=2,180 \mathrm{~min} ; n=3$ ) the mean intrahepatic enrichments of $\mathrm{C} 2$ and $\mathrm{C} 3$ aspartate were

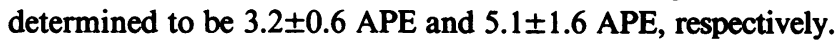

From these data the intrahepatic dilution factor for alanine and lactate as they pass through the OAA pool can be determined by Eq. 3. At $90 \mathrm{~min}$ the dilution factor was calculated to be $2.5 \pm 0.4$ and at $180 \mathrm{~min} 2.3 \pm 0.2(P<\mathrm{NS})$.

Using a mean value of 2.4 for the dilution factor in conjunction with the ${ }^{13} \mathrm{C}$ labeling data in positions $\mathrm{C} 5$ and $\mathrm{C} 6$ glucose (Table I) and C2 and C3 of alanine and lactate (Table II), the percent contribution of alanine plus lactate to newly synthesized glycogen was calculated by Eq. 4 to be $55 \%$.

It should be noted that it is assumed that the enrichments of the metabolites that we measure in the liver extracts represent the enrichments of the metabolites inside the hepatocyte since hepatocytes represent $\sim 78 \%$ of the parenchymal volume (28). Since glutamate and aspartate are $>24$ times more concentrated in the intracellular space than the extracellular space $(29)>99 \%$ of the glutamate/aspartate signal must reflect intracellular enrichments of these metabolites. For lactate (and to some degree alanine), which exist in similar concentrations in blood and the hepatocyte, there will be a larger contribution of the extracellular compartment. Assuming the extracellular space of the liver is $\sim 16 \%$ (28) from our portal vein and liver extract data for lactate ${ }^{13} \mathrm{C}$ enrichments (Tables I and II), it can be calculated that our intrahepatic enrichments for lactate (Table II) would be over-

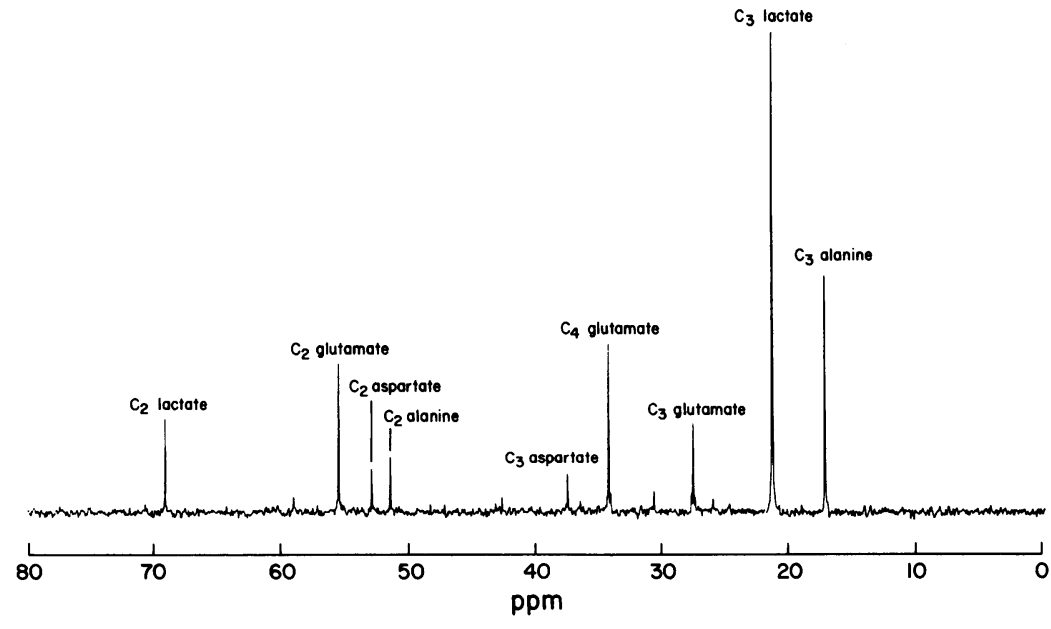

Figure 2. Typical ${ }^{13} \mathrm{C}-\mathrm{NMR}$ spectra acquired at 500 $\mathrm{MHz}$ of semipurified alanine, lactate, aspartate, and glutamate obtained from a PCA extract of liver as described in Methods. 
Table II. Intrahepatic Percent Labeling for Glutamate (G2, G3, G4), Lactate (L2, L3), and Alanine (A2, A3) at 90 min and 180 min

\begin{tabular}{|c|c|c|c|c|c|c|c|}
\hline & Glutamate & & & Lactate & & Alanine & \\
\hline Time & G2 & G3 & G4 & L2 & L3 & A2 & A3 \\
\hline $90^{\prime}$ & 7.6 & 4.6 & 4.5 & 3.1 & 17.7 & 4.8 & 15.9 \\
\hline $90^{\prime}$ & 2.6 & 1.6 & 0.9 & 1.5 & 17.0 & 0 & 13.0 \\
\hline $90^{\prime}$ & 6.4 & 4.4 & 7.7 & 4.0 & 22.7 & 1.5 & 20.7 \\
\hline $90^{\prime}$ & 7.8 & 2.6 & 5.4 & 3.0 & 20.1 & 2.5 & 19.9 \\
\hline Mean \pm SEM & $6.1 \pm 1.2$ & $3.3 \pm 0.7$ & $4.6 \pm 1.4$ & $2.9 \pm 0.5$ & $19.4 \pm 1.3$ & $2.2 \pm 1.0$ & $17.4 \pm 1.8$ \\
\hline $180^{\prime}$ & 5.3 & 4.1 & 6.1 & 2.2 & 22.4 & 3.0 & 19.3 \\
\hline $180^{\prime}$ & 4.4 & 2.6 & 6.4 & 0.3 & 18.7 & 1.3 & 17.9 \\
\hline $180^{\prime}$ & 8.8 & 7.7 & 12.2 & 2.6 & 27.2 & 2.7 & 22.5 \\
\hline $180^{\prime}$ & 7.4 & 5.3 & 9.7 & 1.9 & 23.9 & 3.0 & 21.9 \\
\hline $180^{\prime}$ & 4.5 & 5.3 & 5.1 & 0.9 & 27.9 & 0.8 & 20.9 \\
\hline Mean \pm SEM & $6.1 \pm 0.9$ & $5.0 \pm 0.8$ & $7.9 \pm 1.3$ & $1.6 \pm 0.4$ & $24.0 \pm 1.7$ & $2.2 \pm 0.5$ & $20.5 \pm 0.8$ \\
\hline
\end{tabular}

All values expressed in APE \pm SEM.

estimated by, at most, $9 \%$, which would then cause an underestimation of the contribution of lactate to glycogen synthesis by this much.

\section{Discussion}

It is now becoming apparent that after glucose ingestion in rat and man only one-third of glycogen repletion occurs directly from glucose (glucose $\rightarrow$ glucose-6-P $\rightarrow$ glucose-1-P $\rightarrow$ UDPglucose $\rightarrow$ glycogen). We (6), as well as others $(1-5,7,8)$, have demonstrated that the majority of glycogen formation is derived from a gluconeogenic pathway, possibly from lactate and alanine. However, the precise contribution of these gluconeogenic precursors to glycogen synthesis has been difficult to quantitate because of problems in measuring the dilution of label in pyruvate as it traverses the oxaloacetate pool. In the present study we examined this question by employing NMR spectroscopy in conjunction with ${ }^{3} \mathrm{H}$ and ${ }^{14} \mathrm{C}$ tracer techniques in the awake, unstressed rat.

In order to determine the amount of dilution that occurs from labeled pyruvate as it passes through the OAA pool, it is necessary to isolate from the liver OAA or an intermediate that equilibrates with OAA. At present, it is very difficult to accurately determine the labeling pattern of ${ }^{13} \mathrm{C}$ in OAA from liver extracts. However, the labeling pattern in OAA may be estimated by measuring the labeling pattern of glutamate assuming during steady state the labeling pattern in glutamate reflects the labeling pattern in alpha-ketoglutarate and assuming the latter equilibrates with OAA. The fact that the enrichments we obtained for C2 and C3 aspartate closely matched those for C3 and C2 of glutamate supports this assumption since aspartate directly equilibrates with OAA via aspartate aminotransferase. As can be seen from Fig. 3, carbon atoms in positions 2 and 3 of glutamate are derived from carbon atoms 3 and 2 of alanine/lactate. Therefore, by comparing the enrichment of carbon atoms 2 and 3 of glutamate with carbon atoms 2 and 3 of alanine, an estimate of the dilution of label from pyruvate as it passes through the OAA pool can be determined (Eq. 3). Using this line of reasoning and the data in Table II it can be determined that the dilution factor at $90 \mathrm{~min}$ was $2.5 \pm 0.4$ and at $180 \mathrm{~min}$ was $2.3 \pm 0.2(P$ $<$ NS). It is unclear why this estimate is so much larger than the
1.38 estimate of Hetenyi (10). Although Hetenyi's factor was calculated for $\left[2-{ }^{14} \mathrm{C}\right]$ pyruvate, and our pyruvate was predominantly labeled in the $\mathrm{C} 3$ position, the factor for $\mathrm{C} 3$ pyruvate is in nearly all conditions less than that for $\mathrm{C} 2$ pyruvate (11). The differences between the factors may be related to the different conditions under which the animals were studied. Our animals were assessed in a conscious state under conditions of hyperglycemia and hyperinsulinemia, whereas his animals were studied under anesthesia in a "not fasted" state. It should also be pointed out that our model directly assesses the dilution factor and takes into account the anaplerotic fluxes of glutamate and glutamine into the TCA cycle as well as flux through PDH and PK, which may affect the dilution factor whereas Hetenyi's model does not. From this estimate of the dilution factor and knowledge the ${ }^{13} \mathrm{C}$ labeling pattern in positions C5, C6 of glucose and C2, C3 of alanine/lactate, it can be calculated from Eq. 4 that $\sim 55 \%$ of liver glycogen is derived from alanine/lactate.

From the present experimental data the amount of glucose incorporated into glycogen by the direct pathway can also be calculated. Thus, knowing the enrichment in the $\mathrm{Cl}$ position of glucose of glycogen and in the $\mathrm{Cl}$ position of portal vein glucose, it can be determined from Eq. 1 that $\sim 34 \%$ of liver glycogen is formed by the direct pathway. This is in close agreement with our previously published results (6) and those of others (1-5). A maximum estimate of recycling of glucose $\rightarrow$ triose-phosphate $\rightarrow$ glycogen can also be made from data in Table $I$ as described previously (6) and was found to be $<2 \%$, which agrees with our previous findings (6).

Under steady state conditions the ${ }^{13} \mathrm{C}$ labeling pattern in $\mathrm{C} 2$ through $\mathrm{C} 4$ of glutamate in conjunction with the enrichment in positions 2 and 3 of alanine and lactate can be used to estimate the relative fluxes through pyruvate dehydrogenase/TCA cycle flux and pyruvate kinase/total pyruvate utilization flux (see Appendix). Pyruvate dehydrogenase flux was calculated to represent $24 \pm 6 \%$ of the total TCA cycle flux at $90 \mathrm{~min}$ and increased slightly but not significantly to $35 \pm 5 \%(P=0.18)$ of the TCA cycle flux at $180 \mathrm{~min}$. This increase in flux most likely represents the further time-related activation of pyruvate dehydrogenase by insulin after $90 \mathrm{~min}(30)$. It should be remembered that these animals were studied after a 24-h fast when pyruvate dehydrogenase activity might be expected to be minimal. 
An estimate of pyruvate kinase flux/total pyruvate utilization was also obtained as described in the Appendix and was found to be between $51 \pm 6 \%$ and $31 \pm 6 \%$ at 90 and $180 \mathrm{~min}$, respectively. This reflects a relatively large amount of intrahepatic recycling between phosphoenolpyruvate and pyruvate and is comparable to the data of Friedmann et al. (31) and Rognstad et al. (32) in fed animals in which pyruvate kinase flux was found to be $40-50 \%$ of the gluconeogenic flux in perfused rat liver and isolated hepatocytes. However, it should also be noted that malic enzyme can also scramble label from the $\mathrm{C} 3$ position of pyruvate into the $\mathrm{C} 2$ position that might therefore result in an overestimation of pyruvate kinase flux by this method.

In summary, after glucose ingestion in a 24-h fasted rat direct conversion of glucose to glycogen accounts for approximately one-third of glycogen formation; the average dilution factor for labeled alanine and lactate as they traverse the oxaloacetate pool under the conditions of this study was 2.4 ; using this dilution factor it can be calculated that alanine and lactate via the gluconeogenic pathway accounts for $\sim 55 \%$ of glycogen formation; together alanine/lactate (55\%), glucose $(34 \%)$ can account for almost all of the glycogen formed; pyruvate dehydrogenase flux ranges between 24 and $35 \%$ of total acetyl-CoA production; and pyruvate kinase flux relative to total pyruvate utilization was $\sim 40 \%$.

\section{Appendix}

Single pool model steady state equations for: (refer to Fig. 3).

1. Derivation of pyruvate dehydrogenase flux/TCA cycle flux

Assumptions: 1. No appreciable label entering the TCA cycle from free fatty acid oxidation.

2. Flux into acetyl-CoA from free fatty acids $+\mathrm{c}=\mathrm{e}$ (total acetyl-CoA production = TCA cycle flux, minimum estimate)

3. $\mathrm{P}_{3}=\mathrm{L}_{3}^{*}=\mathrm{A}_{3} *$

$\mathrm{P}_{3} \mathrm{c}=\mathrm{Ac}_{2} \mathrm{e}$

4. $A C_{2}=G_{4}$

$\frac{\mathrm{PDH} \text { flux }}{\mathrm{TCA} \text { flux }}=\frac{c}{e}=\frac{\mathrm{Ac}_{2}}{\mathrm{P}_{3}}=\frac{\mathrm{G}_{4}}{\mathrm{~L}_{3}}$

${ }^{*} \mathrm{~L}_{3}=\mathrm{A}_{3}$ was verified by ${ }^{1} \mathrm{H}$ - and ${ }^{13} \mathrm{C}$-NMR measurements (Table I).

where: $P_{3} ; L_{3} ; A_{3}=$ intrahepatic pyruvate; lactate and alanine enrichments (APE) in carbon position 3.

2. Derivation of pyruvate kinase flux/total pyruvate utilization flux:

Assumptions: $1 . \mathrm{O}_{2}=\left(\mathrm{G}_{2}+\mathrm{G}_{3}\right) / 2$

2. $\mathbf{P}_{2}=\mathbf{L}_{2}$

3. Negligible label in extracellular C2 pyruvate/alanine/ lactate (i.e., negligible amount of gluconeogenesis occurring extrahepatically).

4. Pyruvate kinase flux is much greater than malic enzyme flux.

$\mathrm{O}_{2} j=\mathrm{P}_{2}(c+g+l)$

$\frac{\text { PK flux }}{\text { total pyruvate utilization }}=\frac{(j)}{(c+g+l)}=\frac{P_{2}}{O_{2}}=\frac{L_{2}}{\left(G_{2}+G_{3}\right) / 2}$

where $c+g+1=$ total pyruvate utilization.

\section{Acknowledgments}

The authors would like to thank Betsy Hodgson and Eleanor Andujar for their expert technical assistance, Peter Demou for his assistance with

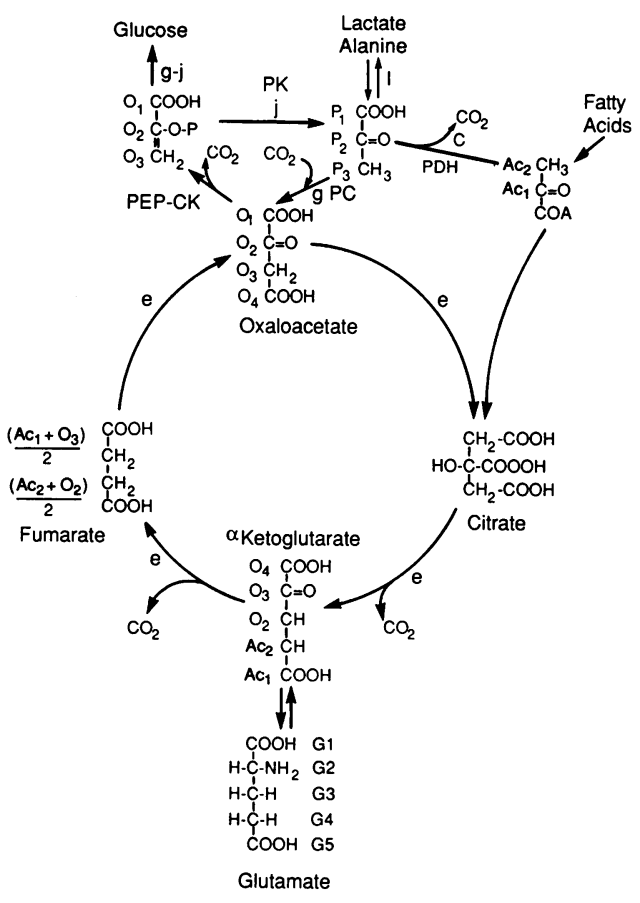

Figure 3. Steady state model of mitochondrial (TCA) cycle and gluconeogenesis used for derivation of PDH flux/TCA cycle flux, PK flux/ total pyruvate utilization flux (adapted from J. Katz, ref. 11). $e$, rate of citrate synthesis or flux in TCA cycle; $g$, rate of oxaloacetate formed from pyruvate catalyzed by pyruvate carboxylase (PC) or phosphoenol-pyruvate carboxykinase (PEP-CK); $c$, rate of acetyl-CoA formation from pyruvate catalyzed by pyruvate dehydrogenase entering TCA cycle; $j$, rate of pyruvate formation from PEP catalyzed by pyruvate kinase (PK); $l$, rate of pyruvate efflux from liver; $(c+g+l)=$ total rate of pyruvate utilization; $\mathrm{O}_{1}, \mathrm{O}_{2}, \mathrm{O}_{3}$ : carbons of oxaloacetate; $\mathrm{Ac}_{1}, \mathrm{Ac}_{2}$ : carbons of acetyl-CoA; $\mathbf{P}_{1}, \mathbf{P}_{2}, \mathrm{P}_{3}$ : carbons of pyruvate; $\mathbf{G 1}$, G2, G3, G4, G5: carbons of glutamate.

the NMR analysis, Ralph Jacobs for his assistance with the amino acid analysis, and Jo Anne Palmieri for her superb secretarial assistance. The authors are also very grateful to Dr. Ralph DeFronzo for his helpful comments and the use of his laboratory and Dr. Robert Shulman for the use of his NMR facility.

This work was supported in part by National Institutes of Health grants AM-01248, AM-27121, AM-17664, and grants from the Juvenile Diabetes Foundation.

\section{References}

1. Radziuk, J. 1982. Sources of carbon in hepatic glycogen synthesis during absorption of an oral glucose load in humans. Fed. Proc. 41:1 10116.

2. Newgard, C. B., L. J. Hirsch, D. W. Foster, and J. D. McGarry. 1983. Studies on the mechanism by which exogenous glucose is converted into liver glycogen in the rat. J. Biol. Chem. 258:8046-8052.

3. Katz, L. D., M. G. Glickman, S. Rapoport, E. Ferrannini, and R. A. DeFronzo. 1983. Splanchnic and peripheral disposal of oral glucose in man. Diabetes. 32:675-679.

4. Newgard, C. B., S. V. Moore, D. W. Foster, and J. D. McGarry. 1984. Efficient hepatic glycogen synthesis in refeeding requires continued carbon flow through the gluconeogenic pathway. J. Biol. Chem. 259: 6958-6963.

5. Scofield, R. F., K. Kosugi, W. C. Schumann, K. Kumaran, and B. R. Landau. 1985. Quantitative estimation of the pathways followed in the conversion to glycogen of glucose administered to the fasted rat. J. Biol. Chem. 260:8777-8782. 
6. Shulman, G. I., D. L. Rothman, D. Smith, C. M. Johnson, J. B. Blair, R. G. Shulman, and R. A. DeFronzo. 1985. Mechanism of liver glycogen repletion in vivo by nuclear magnetic resonance spectroscopy. J. Clin. Invest. 76:1229-1236.

7. Shikama, M., and M. Ui. 1978. Glucose diverts hepatic gluconeogenic product from glucose to glycogen in vivo. Am. J. Physiol. 235: E354-E360.

8. Katz, J., and J. D. McGarry. 1984. The glucose paradox. Is glucose a substrate for liver metabolism? J. Clin. Invest. 74:1901-1909.

9. Krebs, M. A., R. Hems, M. J. Weidemann, and R. N. Speake. 1966. The fate of isotopic carbon in kidney cortex synthesizing glucose from lactate. Biochem. J. 101:242-249.

10. Hetenyi, G., Jr., and C. Ferrarotto. 1983. Correction for metabolic exchange in the calculation of the rate of gluconeogenesis in rats. Biochem. Med. 29:372-378.

11. Katz, J. 1985. The determination of gluconeogenesis in vivo with ${ }^{14} \mathrm{C}$ labelled substrates. Am. J. Physiol. 248:R391-R399.

12. Smith, E. L., B. M. Austen, K. M. Blumathal, and J. F. NYC. 1975. Glutamate Dehydrogenases. In The Enzymes. Vol. XI. P. D. Boyer, editor. Academic Press, Inc., New York. 293-367.

13. Crawford, J. M., and J. J. Blum. 1983. Quantitative analysis of flux of carbon in the gluconeogenic, glycolytic and pentose pathway in hepatocytes from fasted rats. J. Biol. Chem. 212:585-598.

14. Katz, J., and N. Grunnet. 1979. Estimation of metabolic pathways in steady state in vivo. Rates of tricarboxylic acid and pentose cycles. In Techniques in Metabolic Research. H. L. Kornberg, editor. Elsevier/ North-Holland, Amsterdam. Part I, B208, p. 1-18.

15. Blum, J. J., and R. B. Stein. 1982. On the analysis of metabolic networks. In Biological Regulation and Development. R. F. Goldberg and K. R. Yamamoto, editors. Plenum Publishing Corp., New York. 99-125.

16. Wright, B. E., and P. J. Kelly. 1981. Kinetic models of metabolism in intact cells, tissues and organisms. Curr. Top. Cell Regul. 19:103158.

17. Rossetti, L., D. Smith, G. I. Shulman, D. Papachristou, and R. A. DeFronzo. 1987. Correction of hyperglycemia with phlorizin normalizes tissue sensitivity to insulin in diabetic rats. J. Clin. Invest. 79: 1510-1515.

18. Passonneau, J. V. 1974. Methods of Enzymatic Analysis. 2nd ed. Vol. 3. H. U. Bergmeyer, editor. Academic Press, Inc., New York and London, also Verlag Chemie Weinheim. 1468-1472.

19. Moore, S., and W. H. Stein. 1951. Chromatography of amino acids on sulfonated polystyrene resins. J. Biol. Chem. 192:663-681.
20. Campbell, I. D., C. M. Dobson, G. Jeminet, and R. J. P. William. 1974. Pulse NMR methods for the observation and assignment of exchangeable hydrogens: application to bacitracin. FEBS (Fed. Eur. Biochem. Soc.) Lett. 49:115-119.

21. Rothman, D. L., F. Arias-Mendoza, G. I. Shulman, and R. G. Shulman. 1984. A pulse sequence for simplifying ${ }^{1} H$ NMR spectra of biological tissues. J. Magn. Reson. Med. 60:430-436.

22. Rothman, D. L., K. L. Behar, H. P. Hetherington, and R. G. Shulman. 1984. Homonuclear ' $\mathrm{H}$ double-resonance difference spectroscopy of the rat brain in vivo. Proc. Natl. Acad. Sci. USA. 81:63306334.

23. Hers, H. G. 1955. The conversion of fructose-1- ${ }^{14} \mathrm{C}$ and sorbitol$1-{ }^{14} \mathrm{C}$ to liver and muscle glycogen in the rat. J. Biol. Chem. 214:373381.

24. Cook, M., and Y. Lorber. 1952. Conversion of $1-^{14} \mathrm{C}$ mannose and $1 .{ }^{14} \mathrm{C}$ glucose to liver and muscle glycogen in the intact rat. J. Biol. Chem. 199:1-8.

25. Taylor, W. R., and R. G. Langdon. 1956. Intestinal absorption of glucose in the rat. Biochim. Biophys. Acta. 21:384-385.

26. Bishop, J. S., R. Steele, N. Altszuler, A. Dunn, C. Bjerknes, and R. C. DeBodo. 1965. Effects of insulin on liver glycogen synthesis and breakdown in the dog. Am. J. Physiol. 208(2):307-316.

27. Reo, N. V., B. A. Siegfried, and J. H. Ackerman. 1984. Direct observation of glycogenesis and glucagon stimulated glycogenolysis in the rat liver in vivo by high-field carbon-13 surface coil NMR. J. Biol. Chem. 259:13664-13667.

28. Blouin, A., R. P. Bolender, and E. R. Weibel. 1977. Distribution of organelles and membranes between hepatocytes and nonhepatocytes in rat liver parenchyma. J. Cell Biol. 72:441-455.

29. Williamson, D. H., and J. T. Brosnan. 1974. Concentrations of metabolites in animal tissues. H. U. Bergmeyer, editor. Methods of Enzymatic Analysis. Vol. 4. Verlag Chemie, Weinheim, Academic Press, Inc., New York and London. 2266-2302.

30. Randle, P. J., P. H. Sugden, A. L. Kerbey, P. M. Radcliff, and N. J. Hutson. 1978. Regulation of pyruvate oxidation and the conservation of glucose. Biochem. Soc. Symp. 43:47-67.

31. Friedmann, B., E. H. Goodman, H. L. Saunders, V. Kostas, and S. Weinhouse. 1971. An estimation of pyruvate recycling during gluconeogenesis in the perfused rat liver. Arch. Biochem. Biophys. 143:566578.

32. Rognstad, R., and J. Katz. 1977. Role of pyruvate kinase in the regulation of gluconeogenesis from L-lactate. J. Biol. Chem. 252:18311833. 